Yet how can this be when Drs. A, B, and $\mathrm{C}$ are asked to report for one side knowing that Drs. D, E, and $F$ are doing so for the other and all their amour propre is excited to make a valiant effort to minimise the value of the facts and ridicule the conclusions of their opposing colleagues? The climax of absurdity is reached when each side permanently retains a medical man to fight its claims. The medical men in such a position are advocates, able and honourable advocates it is true, but cannot be looked upon as expert witnesses. That each side should have such expert advice is fair enough but it should not come into court as an expounder to the laity of scientific truth.

The present methods of adjudicating these cases are in short fundamentally rotten and stand self-condemned by the pitiable scenes that occur in our law courts and the general travesty of justice to which they lead. The system of Crown referees was intended to avoid this state of things, but for some mysterious reason judges have ignored their existence. Either their activity must be called into being or in some other way independent technical exponents of truth must be found and the scientific expert witness no longer be mixed up with the medical adrocate.

\section{Lookíng JBack.}

\section{THE LANCET, SATURDAY, March 3, 1827.}

TO THE

RIGHT HON. ROBERT PEEL, \&c., \&c.

\section{(From THe TIMES of February 26.)}

SIR,-The high ministerial station which you deservedly occupy, must often expose you to various kinds of applications respecting the condition and management of our national institutions, and also to personal or partial interference about their several real or pretended interests. In all such instances you must perceive the fairness and the ultimate advantage of preferring direct information from the respective constituted authorities. of requiring advice from rival institutions upon doubtful measures, and of regarding with jealousy the private communications of interested individuals. It is, however, reported that you are, at this time, beset upon the subject of introducing an ordeal for licensing man-midwives, by certain members of the London College of Surgeons, and that you are urged by popular men (whose wisdom and disinterestedness may be questioned) to favour their scheme with your powerful influence.

As the prevalent vice of avarice may have some share in this professional movement, it is fit that you and the public should be acquainted with the probably concealed effects of granting the solicited privileges; and for the reasons already given, I am induced to address you through the press.

Man-midwifery has only been practised in England during the last hundred years, and it was introduced as a French fashion. From the beginning it has been strongly opposed on the score of its indecency, by many distinguished and scientific medical men, and also, because the birth of mankind appeared to them to be a purely natural process, so wisely ordered, that it very rarely demands any other aid than experienced mothers can safely give. Even so late as the time of the illustrious mother of his present Majesty, that exemplary Queen was personally attended by good Mrs. Draper, without difficulties or misadventures; whereas the contrary result, under male management, in the fatal affair of the Princess Charlotte and her infant, will be long remembered.

If it should be asked why so many professional men addict themselves to a degrading vocation, it may be answered, that the practice of man-midwifery leads to unlimited power in every family, and thence to lucrative ends. Women, naturally timid, and ignorant of their own structure, are peculiarly exposed, during the most important office of their existence, to the persuasions or menaces of more knowing persons, and they are thence easily made to believe, that the natural and wholesome delays and pains of child-bed are within the control of medical or surgical art,- - an assumption which is too generally acted upon, and with unvarying evil consequences ; because it is a violation of the ways of nature. Man-midwives have continually alleged, that ignorant women practitioners commit many fatal mistakes, and now they present similar objections against unlicensed men. If, as I believe, the safeguards of child-birth are amply provided by nature, and that not one instance in a thousand calls for any other help beyond what any moderately experienced woman can safely give, why are we to license adventurers, who may seek notoriety by desperate acts, often involving manslaughter-operative acts, the moral propriety of which is very doubtful, and the time and the methods for performing them, still subjects for rancorous disputes? But the present affair is not respecting the utility of man-midwives, but the impropriety of empowering any special corporate medical body to coerce the rest ; to further impede female-midwives in a becoming duty, and to deprive delicate women of that great resource of self-respect. Already the prevalence of man-midwifery has driven country surgeons and apothecaries to adopt this humiliating office, and the number of women practitioners has been thence so reduced, that paupers are in many places delivered by apprentice boys under 16 years of age. The Royal College of Physicians in London, who rank the highest for learning and for decorum, have lately rescinded their admission of licentiates in midwifery, whether from considering the practice as derogatory to a physician, or as an overweening privilege toward females and children is not avowed; but it seems that no London physician educated at Oxford or Cambridge, has yet condescended to be a man-midwife. The Royal Colleges of Surgeons in London, in Dublin, and in Edinburgh, have likewise hitherto renounced every connexion with man-midwifery.

The teachers of midwifery are indiscriminately doctors and surgeons, but at this moment the majority of lecturer and superintendents of lying-in charities are physicians, while a multitude of legally appointed sub-physicians (styled apothecaries) are equally entitled, with the other classes of the faculty, to establish tribunals for examining and licensing candidates for man-midwifery, if they could deem it expedient. Finally, it may be noted, that the different classes of man-midwives have never yet agreed among themselves to adopt a common ordeal for certifying the qualifications of their calling, and you may be assured, Sir, that many worldly interests will rage against the establishment of any monopoly of this kind in any single institution, because man-midwifery is the covert way to medical fortunes. If, however, the greediness of a few individuals should expose this subject to free discussion, and the judgment of married men and molest women should be copiously awakened, perhaps the general custom of employing women may be again resorted to, and their competent instruction publicly enforced.

It is said, that our changeable neighbours at Paris are already tired of their fashionable freak, and when our countrywomen reflect, that not one in ten thousand of their sex throughout the globe allow of the presence of a man during the rites of child-bed, they may acquire courage, and unite their efforts to replace the routine of midwifery among themselves. I will not offend you and the public by any observations upon the outrageous stories collected on this occasion, to prove the violent and fatal injuries committed by unlicensed man-midwives, because I think the privilege sought for would increase those evils.

With the greatest respect,

I have the honour to be,

Your very obedient servant

Langham-place, Feb. 19.

ANTHONY CARLISLE.

No'TE :-The above letter, which became notorious, was printed on page 701 of Tre LAroET. The following appears at the bottom of page 712

The Letter of Sir ANTHONY CARLISLE, at page 701, is a curiosity, and just the testaceous sort of thing one would expect from the pen of an OYSTER." 1

1 Sir Anthony Carlisle was dubbed "Oyster" because during the delivery of his Hunterian Oration before the Royal College of Surgeons on Feb. 14th, 1826, he produced inappropriately a large oyster and dissected it and descanted on it with the "most obstinate and tedious minuteness." "Sir A's OYsT FR so completely sickened his auditory, that their frequent ejections of it, by coughing and gulping, hurried him to an abrupt conclusion." (Vide THE Litreet, Feb. 18th, 1826.)

A Centenarian.-At a recent meeting of the Long Ashton (Somerset) board of guardians it was decided to grant extra relief to Mrs. Honor Coleman who attained the age of 104 sears on Feb. 22nd. 